\title{
Extracellular cAMP is sufficient to restore developmental gene expression and morphogenesis in Dictyostelium cells lacking the aggregation adenylyl cyclase (ACA)
}

\author{
Geoffrey S. Pitt, ${ }^{1}$ Raymond Brandt, ${ }^{2}$ Kenneth C. Lin, ${ }^{1}$ Peter N. Devreotes, ${ }^{1}$ and Pauline Schaap ${ }^{2,3}$ \\ ${ }^{1}$ Department of Biological Chemistry, The Johns Hopkins University School of Medicine, Baltimore, Maryland 21287 USA; \\ ${ }^{2}$ Department of Biology, University of Leiden, 2333 AL Leiden, The Netherlands
}

Cell movement and cell-type-specific gene expression during Dictyostelium development are regulated by cAMP, which functions both as an extracellular hormone-like signal and an intracellular second messenger. Previous data indicated that aca $^{-}$mutants, which lack adenylyl cyclase activity, fail to aggregate and do not express cell-type-specific genes. We show here that overexpression of ACG, a constitutively active adenylyl cyclase, which in wild-type cells is only expressed during spore germination, partially restores the coordination of cell movement and completely restores developmental gene expression. The aca $a^{-}$cells can also be induced to develop into viable spores by synergy with wild-type cells and, furthermore, form small but normal fruiting bodies, after a developmentally relevant regimen of stimulation with nanomolar cAMP pulses followed by micromolar cAMP concentrations. $2^{\prime}$-Deoxy cAMP, a cAMP analog that activates the cell-surface cAMP receptors but not cAMP-dependent protein kinase (PKA), also induces fruiting body formation as well as expression of prespore-specific and prestalk-enriched genes in aca $^{-}$cells. Intracellular cAMP levels were not altered in aca ${ }^{-}$cells after stimulation with 2'-deoxy cAMP. Our data indicate that ACA is not required to provide intracellular cAMP for PKA activation but is essential to produce extracellular cAMP for coordination of cell movement during all stages of development and for induction of developmental gene expression.

[Key Words: Dictyostelium discoideum; adenylyl cyclase; gene disruption; morphogenesis; developmental gene expression; cAMP receptor]

Received July 5, 1993; revised version accepted August 30, 1993.

cAMP controls multiple stages of the starvation-induced Dictyostelium developmental program, functioning both as a cell-cell signal and an intracellular second messenger. Initially, extracellular cAMP directs the aggregation of up to $10^{5}$ pluripotent amoebae into a multicellular structure. A few amoebae secrete periodic bursts of cAMP that act as a chemoattractant for surrounding cells and stimulate them to synthesize and secrete additional cAMP. This results in propagation of cAMP waves to cells as far as a centimeter away. The cells aggregate into mounds, which go through various shape changes and form freely migrating slugs that eventually generate fruiting bodies, consisting of a globular spore mass resting atop a column of stalk cells. cAMP oscillations are also presumed to coordinate the cell movement that is responsible for these morphogenetic shape changes.

${ }^{3}$ Corresponding author.
In addition to acting as a chemoattractant, cAMP pulses also induce optimal expression of genes whose products participate in the aggregation process, such as chemotactic cAMP receptors and adhesive contact sites A (CSA) (Darmon et al. 1975; Gerisch et al. 1975). Continuous rather than periodic cAMP stimuli induce the expression of several classes of postaggregative genes, such as the prespore-specific genes and genes preferentially expressed in prestalk cells (Barklis and Lodish 1983; Mehdy et al. 1983; Schaap and Van Driel 1985). Extracellular cAMP exerts its effects analogously to hormones and neurotransmitters through action on the family of G-protein-linked cell-surface cAMP receptors (cARs) (Klein et al. 1988; Saxe III et al. 1991), and it activates a membrane-bound adenylyl cyclase as one of several effectors. Although most of the cAMP synthesized is secreted to mediate cell-cell signaling, some cAMP remains intracellularly and may activate cAMPdependent protein kinase (PKA).

Dictyostelium PKA is a heterodimer of one catalytic 
$(\mathrm{C})$ and one regulatory (R) subunit, and the amino acid sequences of the subunits are each $\sim 50 \%$ identical to their mammalian counterparts (Mutzel et al. 1987; Bürki et al. 1991; Mann et al. 1992). Recent studies demonstrated that inactivation of PKA results in inhibition of both spore and stalk cell differentiation (Mann and Firtel 1991; Harwood et al. 1992a,b; Mann et al. 1992; Hopper et al. 1993), whereas mutants with constitutively active PKA (rdeC mutants) display accelerated postaggregative development and precocious spore and stalk cell differentiation (Simon et al. 1992). Thus, cAMP appears to control development both by acting as a cell-cell signal and by regulating the activity of PKA.

Identification of two adenylyl cyclases in Dictyostelium, ACG and ACA (Pitt et al. 1992), has afforded a new approach to understanding the roles of cAMP in cell differentiation. ACG has a novel structure that resembles the membrane-bound family of guanylyl cyclases. Normally, the expression of $A C G$ is limited to mature fruiting bodies and germinating spores. Cells expressing $A C G$ under control of a heterologous promoter have constitutive, high levels of adenylyl cyclase activity unregulated by either cAMP or guanine nucleotides, and they also secrete cAMP constitutively. ACA, however, is regulated by extracellular cAMP through cARs. It is expressed during aggregation and shares homology in its cytoplasmic domains, as well as an overall topology with the six cloned mammalian adenylyl cyclases. ACA is necessary for aggregation; null mutants created by gene disruption ( $\mathrm{aca}^{-}$cells) are blocked in development and remain as a monolayer when starved. These cells lack adenylyl cyclase activity and thus the ability to synthesize cAMP for cell-cell signaling, although several cAMP-induced responses (e.g., chemotaxis) remain intact.

Although ACA is expressed predominantly during aggregation, some $A C A$ mRNA is present in postaggregative cells. This suggests that ACA may be responsible for morphogenetic cAMP signaling both during and after aggregation and may, furthermore, produce the intracellular cAMP that activates PKA and induces cells to differentiate into stalk or spore cells. We show here that cAMP produced by ACA is an essential extracellular signal for regulation of morphogenetic movement and gene expression in all stages of development, but it is not required as an intracellular messenger for developmental gene expression.

\section{Results \\ ACG rescues morphogenesis in aca-cells}

aca null mutants $\left(\mathrm{aca}^{-}\right)$neither aggregate nor express developmentally regulated genes. We first examined whether these defects could be restored by ACG, the germination-specific adenylyl cyclase, which is not regulated by $\mathrm{G}$ proteins or extracellular cAMP. ACG was expressed under a heterologous promoter in both $\mathrm{aca}^{-}$ $\left(a a^{-} / A C G\right)$ and wild-type (wt/ACG) cells. As a control, we also expressed $A C A$ under the same promoter in $a c a^{-}$cells $\left(a c a^{-} / A C A\right)$. Figure 1 shows that $a c a^{-} / A C A$ cells complete all stages of development at the same rate as wild-type cells; a few cells do not participate in aggregation, and the resulting mounds and fruiting bodies are smaller than wild-type cells. In contrast, aggregation of $a^{-} a^{-} / A C G$ cells is significantly delayed, and time-lapse cinematography of $a c a^{-} / A C G$ cells indicates that aggregation is not mediated by cAMP oscillations. Aggregates continuously form and disintegrate, but eventually some aggregates form small but normal fruiting bodies with spores competent for germination. During aggregation of wt/ACG cells, wave-like movements of amoebae were visible in time-lapse cinematography and the cells formed mounds and streams similar to wild-type cells. Toward the end of aggregation, however, the streams were disrupted at several sites by the formation of small mounds, all of which formed mature fruiting bodies.

The observation that the initial stages of wt/ACG aggregation and the later multicellular stages appeared largely normal, in contrast to aca-/ACG cells, suggests that the presence of ACA, regulated by cAMP and G-proteins, confers on these cells an ability to develop that unregulated ACG cannot replicate by itself.

\section{Rescue of $\mathrm{aca}^{-}$cell differentiation by synergy} with wild-type cells

The observation that $a c a^{-} / A C G$ cells can form fruiting bodies with viable spores suggests that cAMP production, independent of stimulus modulation, is sufficient to induce cell differentiation. It is not clear, however, whether intra- or extracellular cAMP, or both, are required to restore cell differentiation, because $a a^{-} / A C G$ cells produce cAMP intracellularly before they secrete it. We therefore examined whether $\mathrm{aca}^{-}$cells can go through development when provided solely with extracellular cAMP.

One approach to provide $a a^{-}$cells with an exogenous source of cAMP is to synergize them with wild-type cells. Ax-3, $\mathrm{Cca}^{-}$, and a mixture of equal numbers of Ax-3 and $a c a^{-}$cells were plated on agar for $36 \mathrm{hr}$; resulting spores were collected and freeze-thawed to kill any remaining amoebae. Multiple loopfuls from the $a c a^{-}$ monolayer were treated identically to ensure that the treatment removed all contaminating amoebae. Aliquots were plated clonally on a bacterial lawn, and the resulting colonies were scored for aggregation. Whereas all colonies from the wild-type spores aggregated, no colonies were detected from the $\mathrm{aca}^{-}$sample, demonstrating that $a c a^{-}$cells cannot form spores independently. Of $230 \mathrm{col}-$ onies examined from the aca-/Ax-3 synergy, $37(16 \%)$ did not aggregate, identifying them as $a c a^{-}$cells. This indicated that $a \mathrm{ca}^{-}$cells were able to enter the development program and form spores when synergized with wild-type cells, although not as efficiently as wild-type cells.

Time-lapse cinematography showed that a portion of cells in $a c a^{-} / \mathrm{Ax}-3$ mixtures were left behind during aggregation and that cells continually left the chimerical structures. We assume that the low percentage of $a a^{-}$ 
Pitt et al.

Figure 1. Developmental phenotypes of wild-type, $a c a^{-} / A C A, a c a^{-} / A C G$, and wt/ $A C G$ cells. Cells were allowed to develop on PB agar plates and imaged with timelapse cinematography. Prints from the video images were captured with a video printer. All images were examined at the same magnification, except for wt/ACG cells, which were magnified 2.5 -fold higher. The time of development is indicated for each image. Sequentially shown are the following: (Wildtype cells) Streaming aggregates, a forming mound, slug formation, mature culminants (visualized directly from above); $\mathrm{aca}^{-} /$ $A C A$ cells| early aggregates, formation of mounds, same mounds showing early tips, early culmination; ( $a \mathrm{ca}^{-} / \mathrm{ACG}$ cells) early aggregates, later aggregates, appearance of mounds, tip formation; and (wt/ACG) cells, edge of a stream (equivalent to the end of a stream in the first wild-type frame), beginning of the disruption of the stream, the formation of several mounds from one stream, the formation of early culminants.

spores in chimeras is the result of the failure of $a \mathrm{ca}^{-}$ cells to participate in morphogenetic movement rather than a defect in cell differentiation.

\section{Extracellular cAMP restores gene expression and morphogenesis}

The observation that wild-type cells could induce $a a^{-}$ cells to form spores was extended by examining whether $\mathrm{aca}^{-}$cells express the different subclasses of cAMP-regulated genes when challenged with cAMP stimuli. Earlier studies showed that expression of aggregative genes can be effectively induced by cAMP pulses in the nanomolar range, whereas expression of postaggregative genes requires stimulation with micromolar cAMP concentrations. Optimal competence for induction of postaggregative gene expression is achieved by pretreating cells for a few hours with nanomolar cAMP pulses (Schaap et al. 1986).

Gene expression in $\mathrm{aca}^{-}, a \mathrm{Ca}^{-} / A C G$, and wild-type cells during development on agar was compared with that induced by treatment of cell suspensions with extracellular cAMP. Figure 2 shows that $a a^{-}$cells do not express the aggregative gene $C S A$ and the prespore gene D19 when incubated on agar. However, CSA gene expression is completely restored by stimulation with cAMP pulses, and D19 expression can be induced to nor-

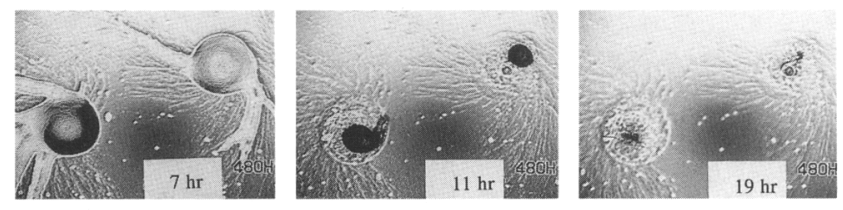

wild-type
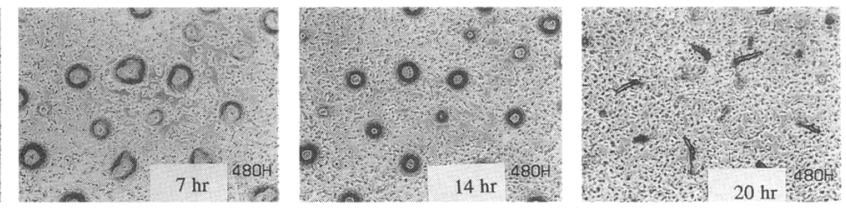

aca- $/ A C A$
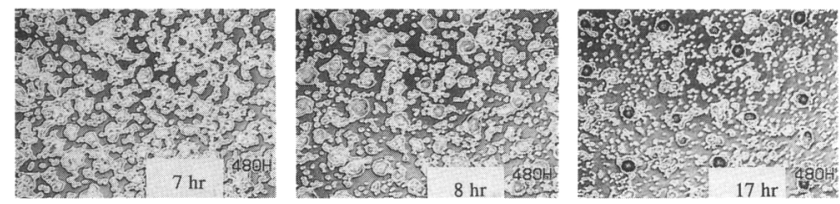

aca-/ACG
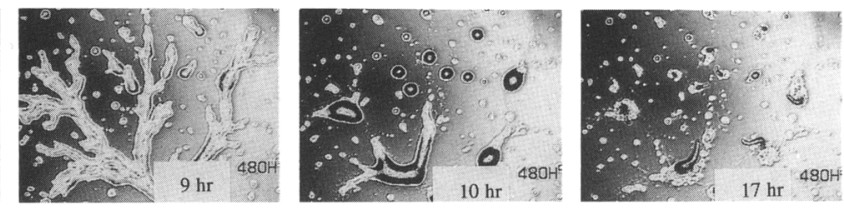

$w t / A C G$ mal levels by further stimulation with micromolar cAMP concentrations.

After $4 \mathrm{hr}$ of stimulation with pulses, $a c a^{-}$cells have formed loose aggregates, which completely dissociate when cells are plated on agar. After subsequent treatment with $300 \mu \mathrm{M} / \mathrm{hr}$ of cAMP or 2'-deoxy cAMP, however, $\mathrm{aca}^{-}$cells have formed tight aggregates. When these are plated on agar, some tiny slugs and fruiting bodies are formed, consisting of a slender stalk supporting viable spores (see Fig. 5, below). The major part of the aggregates will eventually disaggregate into single cells. $a c a^{-} / A C G$ cells express CSA and D19 similarly to wildtype cells during development on agar and during stimulation with cAMP.

To check whether the different cAMP stimulation regimes did not lead to premature expression of ACG in $\mathrm{aca}^{-}$cells, we examined $A C G$ mRNA levels during the experiment. No expression of $A C G$ was detectable in Ax-3 and $\mathrm{aca}^{-}$cells, whereas the gene was expressed during all incubation regimes of $a c a^{-} / A C G$ cells (Fig. 2). Figure 3 shows a compilation of data on expression of a number of developmentally regulated genes in the three strains. The upper panel shows that in $\mathrm{Cad}^{-}$cells, the expression of the aggregative genes CSA and CAR1 is restored to wild-type levels by stimulation with cAMP pulses. Expression of CP2 and RAS, two cAMP-regulated genes that are preferentially expressed in prestalk cells (middle panel), as well as expression of the prespore 


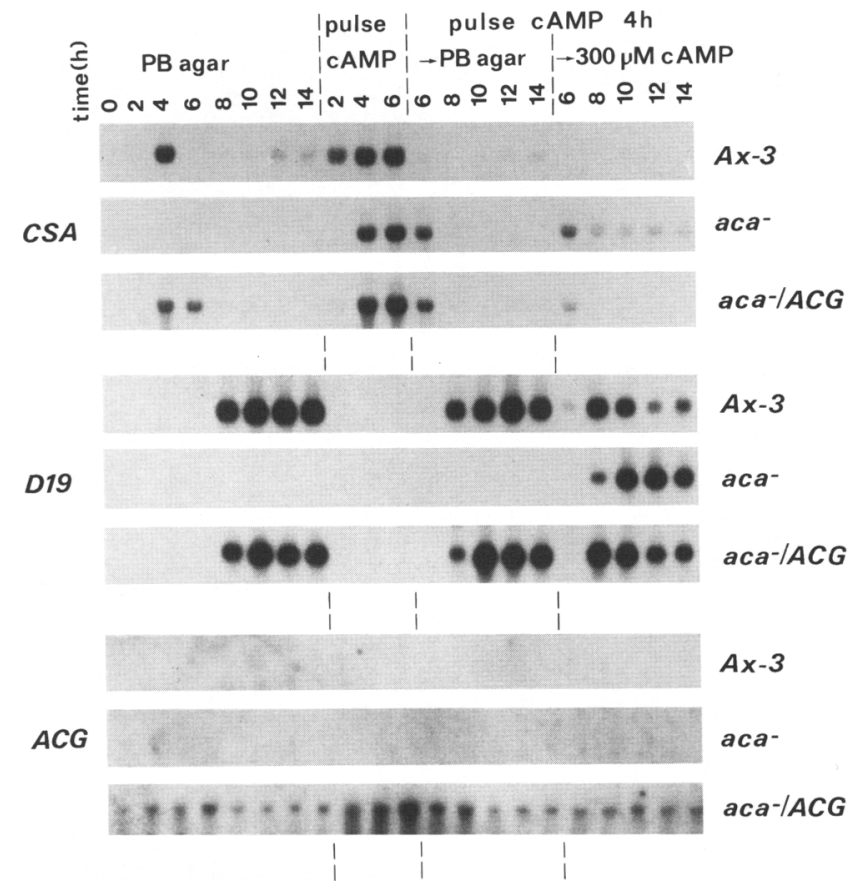

Figure 2. Gene expression in adenylyl cyclase mutants. Ax-3, $a \mathrm{Ca}^{-}$, and $\mathrm{aca}-\mathrm{ACG}$ cells were either incubated for $14 \mathrm{hr}$ on $\mathrm{PB}$ agar or shaken in $\mathrm{PB}$ at $10^{7}$ cells $/ \mathrm{ml}$ and stimulated every 6 min with 30 nM cAMP pulses. After 4 hr of incubation, a portion of the cell suspension was harvested and either incubated on $\mathrm{PB}$ agar or resuspended in $\mathrm{PB}$ and stimulated with $300 \mu \mathrm{M}$ CAMP, which was added at 60 -min intervals for an additional 10 -hr period. RNA was extracted from samples every $2 \mathrm{hr}$, and Northern transfers were probed with ${ }^{32} \mathrm{P}$-labeled D19, CSA, and $A C G$ DNA probes.

genes $D 19, S P 96$, and $S P 70$ (lower panel) is restored by micromolar cAMP stimuli. These data indicate that stimulation with extracellular cAMP is sufficient to restore expression of all classes of cAMP-regulated genes in cells lacking adenylyl cyclase activity.

\section{Effects of stimulus modulation on aggregative gene expression}

During development on agar, $a a^{-} / A C G$ cells show somewhat reduced, but otherwise normal, expression of CSA and $C A R 1$. This is somewhat unexpected because these genes are optimally induced by pulses rather than by the continuous CAMP signal that ACG produces. A possible explanation could be that an active ACA might mediate adaptation to constant stimuli. We compared the efficacy of $30 \mathrm{nM}$ cAMP pulses at 6-min intervals, a continuous influx of 5 or $50 \mathrm{nM} / \mathrm{min} \mathrm{cAMP}$, and $300 \mu \mathrm{M}$ cAMP pulses at 60-min intervals on expression of CSA and $c A R 1$ in wild-type, $a c a^{-}$, and $a c a^{-} / A C G$ cells (Fig. 4). It appeared that for all three strains, nanomolar CAMP pulses were most efficient, whereas constant cAMP fluxes and micromolar cAMP were almost completely ineffective. So cAMP induction of aggregative gene expression is subjected to adaptation in all three cell lines.
This remains difficult to reconcile with the observation that $a_{c a}^{-} / A C G$ cells do express CSA and $c A R 1$ when developing on agar. Possibly these cells can create temporal CAMP concentration differences by moving around the plate.

\section{Stimulation of surface cAMP receptors is sufficient to restore development}

Our observations that stimulation with extracellular cAMP suffices to induce aggregative, prespore- and prestalk-related gene expression in $a c a^{-}$cells suggests that intracellular cAMP and therefore PKA activation is not required. To confirm this and to rule out the possibility that incubation with $300 \mu \mathrm{M}$ cAMP leads to leakage of cAMP into the cells, we investigated whether 2 'deoxy CAMP, a CAR agonist that binds only weakly to PKA (De Wit et al. 1982), can mimic the effects of cAMP on induction of postaggregative gene expression.

As shown above and in Figure 5A, there was no expression of the developmental gene markers in $a \mathrm{ca}^{-}$ cells without the addition of nucleotide. Either cAMP or 2 '-deoxy CAMP, however, was sufficient to induce expression, demonstrating that cAMP exerts its effect on the family of cARs rather than on PKA. Tight aggregates that had formed after incubation of $\mathrm{aca}^{-}$cells with $2^{\prime}$ deoxy cAMP were plated on agar and formed tiny but normal looking slugs and fruiting bodies (Fig. 5B). This experiment demonstrates that after initiating development with exogenous cAMP, $a c a^{-}$cells can form both stalk and spore cells without any further treatment. The $A C A$ locus was examined by Southern blot analysis in cells germinated from these spores and was shown to harbor the disruption identical to $a c a^{-}$cells (data not shown).

\section{cAMP and $c G M P$ responses in aca ${ }^{-}$cells}

Our observations that $\mathrm{aca}^{-}$cells can be induced to form spore and stalk cells in the absence of agents that activate PKA appear to contrast data from other groups, which suggest that PKA is necessary in late development (Mann and Firtel 1991; Harwood et al. 1992b, Mann et al. 1992; Hopper et al. 1993).

To substantiate earlier data that $a \mathrm{ca}^{-}$cells do not contain adenylyl cyclase activity, we also measured whether these cells can produce cAMP in the presence or absence of stimulation of surface cAMP receptors. $a c a^{-}$and Ax-3 cells were stimulated for $5 \mathrm{hr}$ with $30 \mathrm{nM}$ pulses of cAMP, to obtain optimal responsiveness to the cAMP signal, and then equilibrated with $\left[{ }^{3} \mathrm{H}\right]$ adenine. After stimulation with cAMP, cells were lysed in acid and ${ }^{3} \mathrm{H}$ labeled cAMP was purified by column chromatography for quantification. Figure 6A demonstrates that after 2 min of stimulation, Ax-3 cells were able to synthesize at least 15-fold higher levels of cAMP than $a c a^{-}$cells, with the latter showing no significant increase in cAMP synthesis at all. In similarly prepared cells, activation of guanylyl cyclase was measured (Fig. 6B). The $a c a^{-}$cells 
Pitt et al.

Figure 3. Expression of multiple gene classes in adenylyl cyclase mutants. Northern transfers obtained from the experiment described in Fig. 2 were probed with two aggregative genes, CSA and $C A R 1$ (top); two prestalk-enriched genes, CP2 and RAS (middle); and three prespore genes, D19, SP96, and SP70 (bottom). To compare mRNA levels in the three strains, bands on autoradiographs were quantitated by optical density scanning. All data in the top panel are presented as percentage of CSA or $C A R 1$ mRNA levels in Ax-3 cells after $6 \mathrm{hr}$ of stimulation with $30 \mathrm{nM}$ cAMP pulses. Data in the middle panel are expressed as percentage of CP2 or RAS mRNA levels in Ax-3 cells after $2 \mathrm{hr}(t=6)$ or $10 \mathrm{hr}(t=14)$, respectively, of stimulation with $300 \mu \mathrm{M}$ cAMP. Data in the bottom panel are expressed as percentage of $D 19, S P 96$, and $S P 70$ mRNA levels in Ax-3 cells after $4 \mathrm{hr}(t=8)$ of stimulation with $300 \mu \mathrm{M}$ cAMP.

retained the ability to activate guanylyl cyclase in response to cAMP.

\section{Discussion}

We investigated the role of ACA in morphogenetic movement and cell differentiation. This enzyme, which is activated indirectly by the binding of its product to surface receptors interacting with $G$ proteins, accounts for the major adenylyl cyclase activity during Dictyostelium development. The present study leaves no doubt for its role in the aggregation process; the oscillatory cell movement that characterizes Dictyostelium discoideum aggregation is absent from $a a^{-}$cells and from $a a^{-}$ cells expressing $A C G$, a constitutively active adenylyl cyclase. These aca-/ACG cells aggregate inefficiently, in a fashion resembling Dictyostelium minutum, a species that secretes chemoattractant continuously (Gerisch 1964). aca- cells do not aggregate at all, not even after synthesis of proteins required for aggregation (cAMP receptors, etc.) has been induced by exogenous cAMP pulses. It is therefore clear that the cAMP oscillations that control Dictyostelium aggregation result from the specific regulation of the ACA enzyme.

Postaggregative cell movement is controlled by a small group of cells called the tip, which functions as a classical embryological organizer (Raper 1940). A recent study showing that movement of individual cells in slugs occurs in an oscillatory fashion (Siegert and Weijer 1992), combined with earlier evidence for cAMP waves originating from tips in D. minutum aggregates (Schaap et al. 1984), suggested that Dictyostelium tips organize development by acting as autonomous cAMP oscillators. The present data support this hypothesis but also indicate that CAMP oscillations are not absolutely essential for multicellular morphogenesis, because $a c a^{-}$cells can form tiny slugs and fruiting bodies after postaggregative genes have been induced by exogenous cAMP. The observation that $a_{c a}^{-} / A C G$ cells can form fruiting bodies, although somewhat inefficiently, shows that CAMP signal modulation is not strictly essential. The presence of properly regulated ACA in ACG overexpressors completely restores morphogenesis, indicating that in $\mathrm{aca}^{-} /$ $A C G$ cells it is not the presence of unregulated ACG but

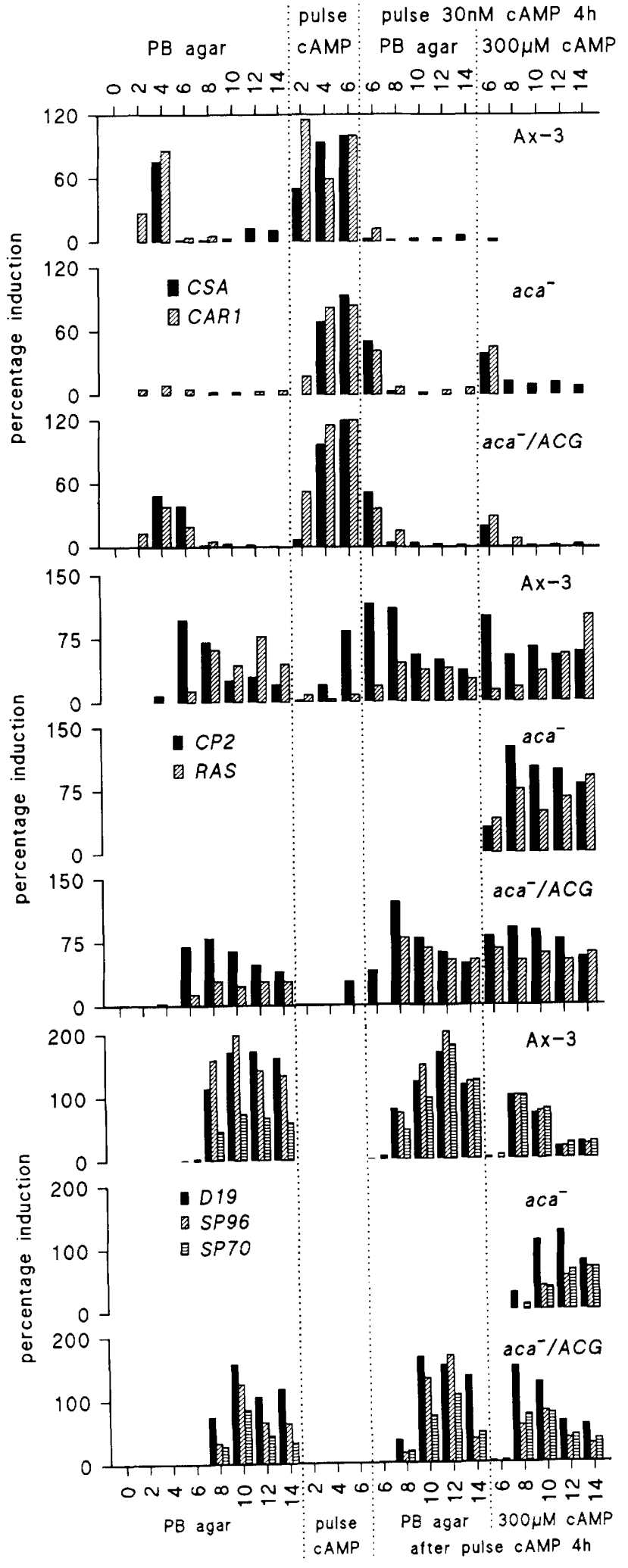

the absence of ACA that prevents normal morphogenetic movement. We conclude that similar to aggregation, postaggregative cell movement is coordinated by prop- 


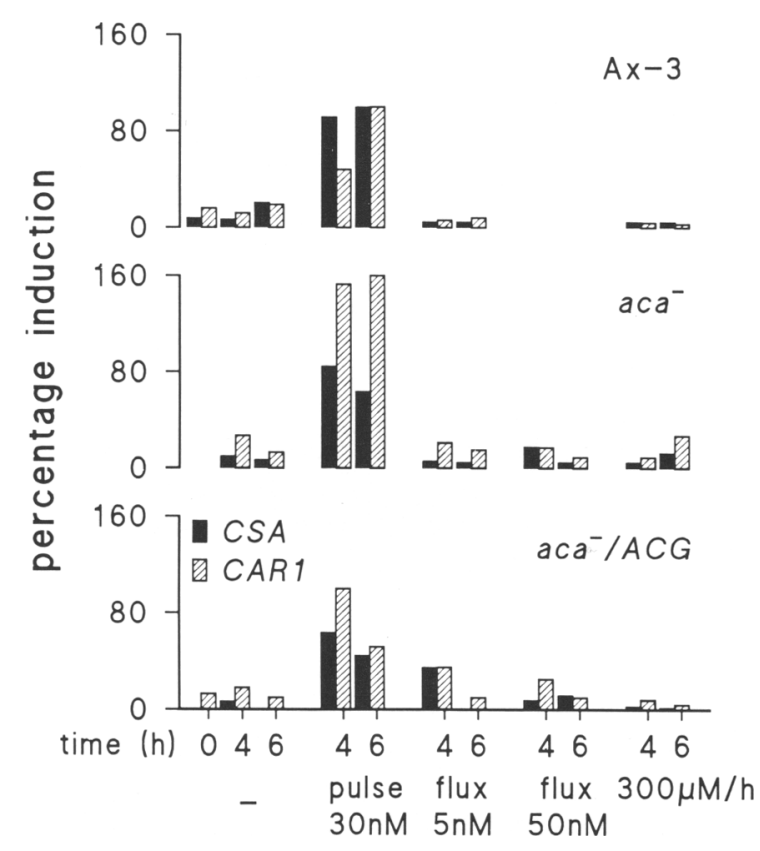

Figure 4. Effect of stimulus modulation on aggregative gene expression. Ax-3, aca ${ }^{-}$, and $a a^{-} / A C G$ cells were shaken in $\mathrm{PB}$ at $10^{7} \mathrm{cells} / \mathrm{ml}$ and stimulated with cAMP delivered as $30 \mathrm{nM}$ pulses at $6-\mathrm{min}$ intervals, as a continuous influx of 5 or 50 $\mathrm{nM} / \mathrm{min}$, or as a $300 \mu \mathrm{M}$ pulse at $60-\mathrm{min}$ intervals. RNA was extracted from cells at the indicated time points, and Northern transfers were probed with ${ }^{32} \mathrm{P}$-labeled $C S A$ and $C A R 1$ cDNA. Data obtained from optical density scans are presented as percentage of mRNA levels in Ax-3 cells after $6 \mathrm{hr}$ of $30 \mathrm{nM}$ cAMP pulses.

erly regulated ACA activity. It appears that slugs may have a "backup" mechanism, which can partially substitute the cAMP signaling system. A possible candidate is the folate signaling system used by vegetative cells, because folate-induced responses were found to reappear after aggregation (Tillinghast and Newell 1984,1987).

The other important outcome of the present study is that ACA is essential for all types of cAMP-regulated gene expression. Neither the aggregative genes, which are expressed in response to nanomolar cAMP pulses, nor the postaggregative prespore- and prestalk-enriched genes are expressed in $a c a^{-}$cells, but expression can be completely restored by exogenous cAMP stimuli. The ability to go through development can also be restored by synergy with wild-type cells, which supposedly supply the $a c a^{-}$cells with the appropriate cAMP signals. The cAR agonist 2'-deoxy cAMP, which binds weakly to PKA, is almost as effective as cAMP in restoring gene expression, indicating that extracellular cAMP acting via cARs and produced by ACA is essential for induction of gene expression. This conclusion is supported by recent observations that membrane-permeable nonhydrolyzable PKA agonists, which can induce at least one PKAmediated response (receptor down-regulation), cannot induce expression of aggregative genes, prespore genes, and prestalk-related genes. These genes are expressed ex- clusively in response to stimulation with cAR agonists (Schaap et al. 1993).

In many eukaryotic systems, gene expression is controlled by intracellular cAMP, which, mediated through
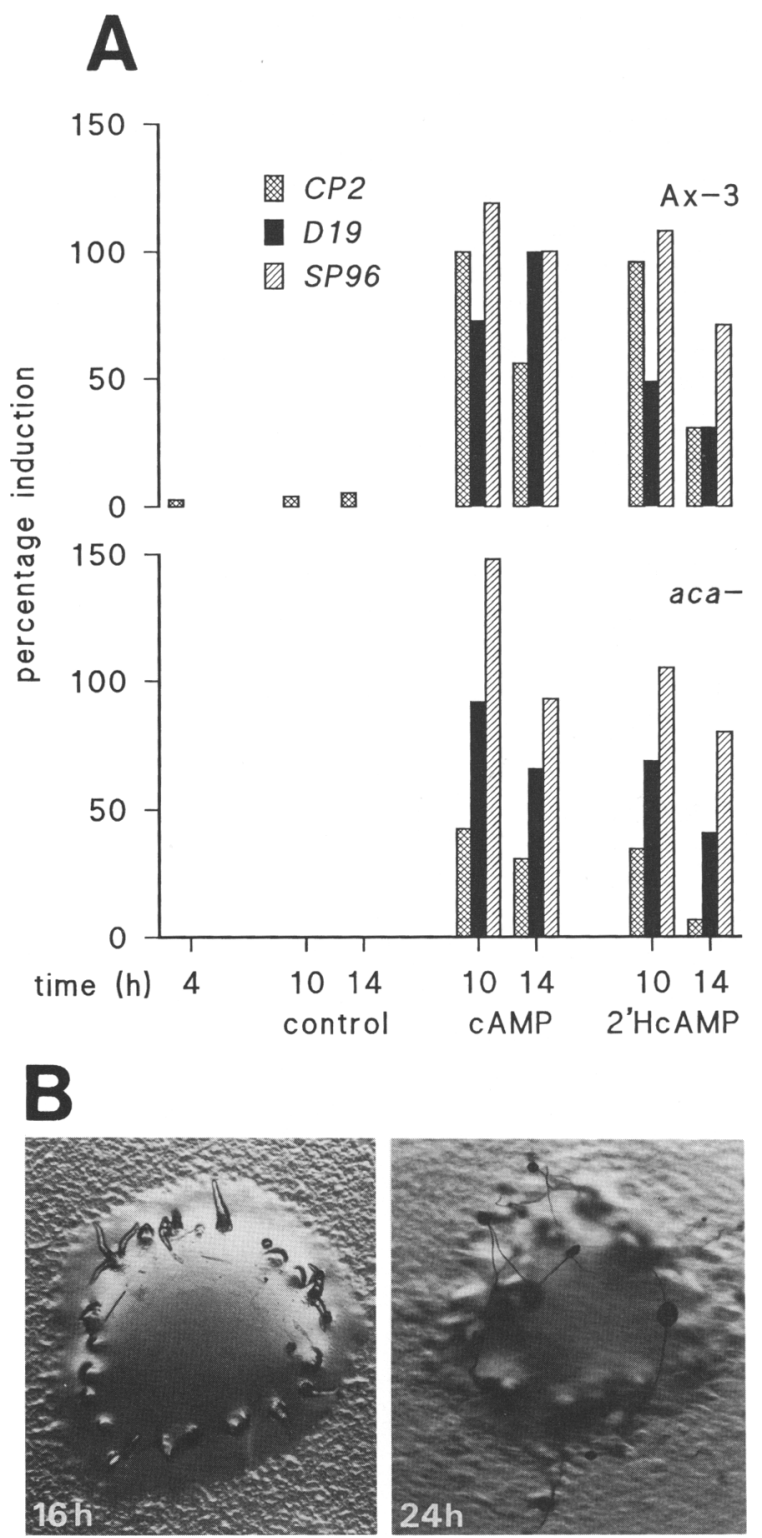

Figure 5. Induction of gene expression and development by a specific CAR agonist. $(A) \mathrm{Ax}-3$ and $a \mathrm{Ca}^{-}$cells were stimulated for $4 \mathrm{hr}$ with $30 \mathrm{nM}$ CAMP pulses, washed with $\mathrm{PB}$, and subsequently incubated at $2 \times 10^{7}$ cells $/ \mathrm{ml}$ for an additional $8 \mathrm{hr}$ period in the absence of stimulus, with $300 \mu \mathrm{M}$ cAMP or with $300 \mu \mathrm{M} 2^{\prime}$-deoxy cAMP added at 60-min intervals. RNA was extracted after 4,10 , and $12 \mathrm{hr}$ from the onset of incubation. mRNA levels, quantitated by optical density scanning, are presented as the percentage of mRNA levels in Ax-3 cells incubated with $300 \mu \mathrm{M}$ cAMP for $6 \mathrm{hr}(C P 2)$ or $8 \mathrm{hr}$ (D19 and SP96). (B) $\mathrm{aca}^{-}$cells, treated for $8 \mathrm{hr}$ with 2'-deoxy cAMP, had formed tight aggregates, which were deposited on $\mathrm{PB}$ agar. Shown are tiny slugs and fruiting bodies that formed after 16 and $24 \mathrm{hr}$ of development. The major part of the aggregate has dissociated into single cells. 


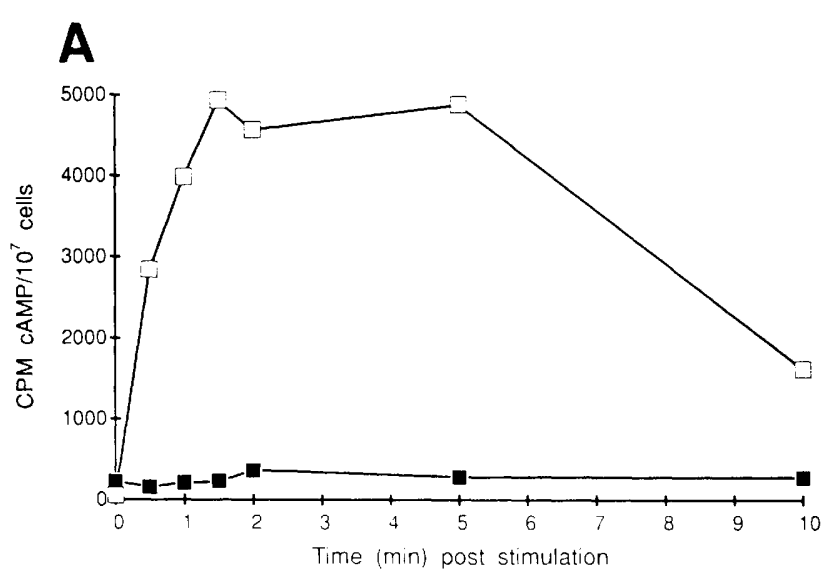

B

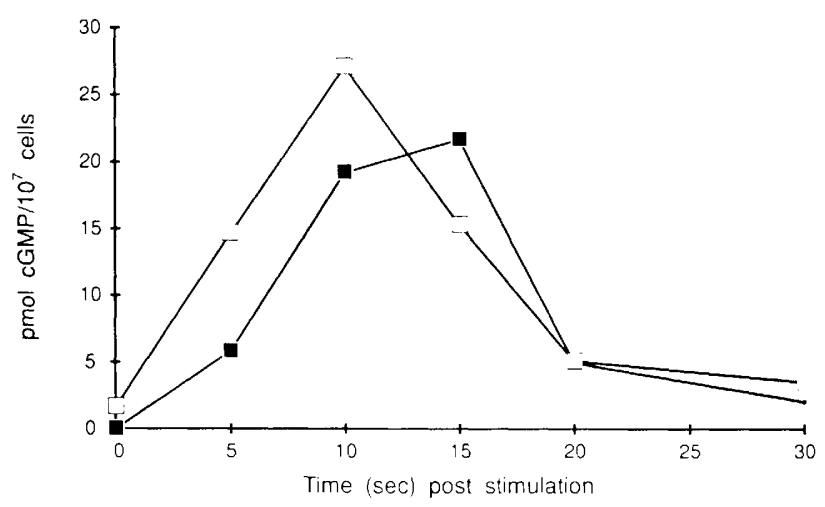

Figure 6. cAMP stimulated CAMP and cGMP response in aca cells. $\langle A| \mathrm{aca}^{-}(\mathbf{C})$ and Ax-3 (D) cells were stimulated for $5 \mathrm{hr}$ with $30 \mathrm{nM}$ cAMP pulses. Cells were then equilibrated with $\left[{ }^{3} \mathrm{H}\right]$ adenine for an additional hour, washed, and stimulated with $1 \mu \mathrm{M}$ cAMP. Reactions were terminated at the indicated time points, and ${ }^{3} \mathrm{H}$-cAMP was purified by column chromatography and measured by scintillation counting. $(B) a c a^{-}$and Ax-3 cells were stimulated for $5 \mathrm{hr}$ with $30 \mathrm{nM}$ cAMP pulses. Cells were washed and then stimulated with $100 \mathrm{nM}$ cAMP. cGMP levels were measured at the indicated time points by radioimmunoassay.

PKA, activates cAMP response elements (CREs) in promoter sequences (Roesler et al. 1988). Several approaches have demonstrated that in Dictyostelium, as well, PKA activation is essential for development. Mutants that lack the PKA-C subunit or that overexpress constitutively native or dominant-negative PKA-R subunits (lacking cAMP binding sites) can neither develop autonomously nor in synergy with wild-type cells (Simon et al. 1989; Firtel and Chapman 1990; Mann and Firtel 1991; Mann et al. 1992). Cell lines that express dominant-negative PKA-R subunits under a prestalk or prespore promoter cannot differentiate into stalk or spore cells, respectively (Harwood et al. 1992a,b; Hopper et al. 1993). In addition, $r d e C$ mutants and cell lines overexpressing PKA-C show accelerated development and a sporogenous phenotype (Anjard et al. 1992; Simon et al. 1992).

Our present study seems to contradict this ubiquitous role for PKA in stalk and spore differentiation, because in $\mathrm{aca}^{-}$cells the expression of developmental markers as well as differentiation into stalk and spore cells can be restored by solely activating surface cAMP receptors and not PKA. One explanation for this discrepancy could be that the PKA-C subunit can be active in the absence of cAMP. This is possible because in Dictyostelium the $\mathbf{R}$ and $C$ subunits are only loosely associated (De Gunzburg et al. 1984). Alternatively, the cells could produce an excess of $C$ over $R$ subunits. Another possibility is that the enzyme is activated by other agents besides cAMP. This is feasible because the Dictyostelium C subunit shows an unusually long amino-terminal extension, which may function as a second regulatory region. $\mathrm{Cu}$ riously, overexpression of the amino-terminal domain lacking the sequences for catalytic activity and interaction with $\mathrm{R}$ subunit also produces a rapid developing phenotype (Anjard et al. 1992). This cell line, however, is not sporogenous, which would suggest that only one of the two functions of PKA-C can be activated solely by the amino terminus of the enzyme. Finally, at present, we cannot rule out that a low level of cAMP is present in $\mathrm{aca}^{-}$cells. Basal cGMP is present at higher levels than cAMP, and receptor-mediated increases in cGMP accumulation are normal in $a a^{-}$cells. It is possible that cGMP might induce some PKA activation.

To conclude, our data prove that ACA activation is not required for the cAR-mediated regulation of spore and stalk cell formation. Although we cannot exclude that a tonically active PKA is also required, the restoration of $\mathrm{aca}^{-}$development by exogenous cAMP strongly suggests that the cARs function through a pathway that is independent of PKA activation. The predominant and essential role of ACA during Dictyostelium development is to provide properly modulated extracellular cAMP signals for coordination of cell movement and induction of developmental gene expression.

\section{Materials and methods}

\section{Materials}

$\left[{ }^{32} \mathrm{P}\right] \mathrm{dATP},\left[2,8 \cdot{ }^{3} \mathrm{H}\right]$ adenine, and cGMP-RIA kits were obtained from Amersham (UK); 2'-deoxyadenosine $3^{\prime}: 5^{\prime}$ monophosphate $\left(2^{\prime}\right.$-deoxy cAMP), G418, and dithiothreitol were from Sigma. CSA, SP70 and SP96, and CP2 and RAS DNA probes were gifts of Drs. A. Noegel (Max-Planck-Institut für Biochimie, Martinsreid, Germany), W.F. Loomis (University of California, San Diego), J.G. Williams (ICRF Clare Hall Laboratories, South Mimms, UK), and C.D. Reymond (Institut d'Histologie et d'Embryologie, Lausanne, Switzerland), respectively.

\section{Cell incubation for gene induction experiments}

$\mathrm{Ax}-3, \mathrm{aca}^{-}$, and $a \mathrm{ca}^{-} / \mathrm{ACG}$ cells were grown in HL5 axenic medium, supplied with $20 \mu \mathrm{g} / \mathrm{ml}$ of G418 for $a \mathrm{ca}^{-} / A C G$. Cells were harvested from growth media in early stationary phase and either resuspended to $10^{7}$ cells $/ \mathrm{ml}$ in $10 \mathrm{mM} \mathrm{Na} / \mathrm{K}$ phosphate buffer at $\mathrm{pH} 6.5(\mathrm{~PB})$, and shaken at $150 \mathrm{rpm}$ and $22^{\circ} \mathrm{C}$ or incubated on PB agar at $2.6 \times 10^{6} \mathrm{cells} / \mathrm{cm}^{2}$.

\section{RNA isolation and analysis}

Total RNA was isolated from $2 \times 10^{7}$ cells and purified by phe$\mathrm{nol} / \mathrm{chloroform}$ extraction and two ethanol and one LiCl pre- 
cipitation steps (Nellen et al. 1987). RNA was size-fractionated on $1.5 \%$ agarose gels containing $2.2 \mathrm{M}$ formaldehyde, transferred to GeneScreen membranes, and hybridized to $\left[\alpha^{-32} \mathrm{P}\right] \mathrm{dATP}-\mathrm{a}$ beled DNA probes according to standard procedures. Autoradiographs were quantitated by optical density scanning, using an LKB Ultroscan densitometer.

\section{cAMP and cGMP responses}

To obtain optimal cAMP and cGMP responses, cells were harvested during exponential phase, resuspended in $\mathrm{PB}$ agar at $10^{7}$ cells $/ \mathrm{ml}$, and stimulated with $50 \mathrm{nM}$ cAMP pulses for $5 \mathrm{hr}$. To measure the cAMP response, cells were shaken for an additional hour in $\left[2,8-{ }^{3} \mathrm{H}\right]$ adenine, washed extensively, and resuspended to $8 \times 10^{7}$ cells $/ \mathrm{ml}$. After stimulation with $1 \mu \mathrm{M}$ cAMP and 10 mM DTT, cells were removed at the appropiate times into a solution of $8 \%$ formic acid and $1 \mathrm{mM}$ cAMP. Samples were vortexed and spun for $5 \mathrm{~min}$ at $10,000 \mathrm{~g}$. The supernatant was lyophilized and resuspended in water for column chromatography as described by Salomon (1979).

To measure the cGMP response, pulsed cells were washed and resuspended to $10^{8} \mathrm{cells} / \mathrm{ml}$. A $100-\mu \mathrm{l}$ sample of cells was stimulated with $20 \mu \mathrm{l}$ of $600 \mathrm{nM}$ cAMP, and reactions were terminated by the addition of $100 \mu \mathrm{l}$ of $3.5 \%$ perchloric acid. Samples were neutralized with $50 \mu \mathrm{l}$ of $50 \%$ saturated $\mathrm{KHCO}_{3}$, and CGMP concentrations were determined by radioimmunoassay (Van Haastert 1985).

\section{References}

Anjard, C., S. Pinaud, R.R. Kay, and C.D. Reymond. 1992. Overexpression of $D d$ PK2 protein kinase causes rapid development and affects the intracellular cAMP pathway of Dictyostelium discoideum. Development 115: 785-790

Barklis, E. and H.F. Lodish. 1983. Regulation of Dictyostelium discoideum mRNAs specific for prespore or prestalk cells Cell 32: 1139-1148.

Bürki, E., C. Anjard, J.-C. Scholder, and C.D. Reymond. 1991. Isolation of two genes encoding putative protein kinases regulated during Dictyostelium discoideum development. Gene 102: 57-65.

Darmon, M., P. Brachet, and L. Pereira Da Silva. 1975. Chemotactic signals induce cell differentiation in Dictyostelium discoideum. Proc. Natl. Acad. Sci. 72: 3163-3166.

De Gunzburg, J., D. Part, N. Guiso, and M. Véron. 1984. An unusual adenosine 3' 5 '-phosphate dependent protein kinase from Dictyostelium discoideum. Biochemistry 23: 38053812.

De Wit, R.J.W., J.C. Arents, and R. Van Driel. 1982. Ligand binding properties of the cytoplasmic cAMP-binding protein of Dictyostelium discoideum. FEBS Lett. 145: 150-154.

Firtel, R.A. and A.L. Chapman. 1990. A role for cAMP-dependent protein kinase in early Dictyostelium development. Genes \& Dev. 4: 18-28.

Gerisch, G. 1964. Die Bildung des Zellverbandes bei Dictyostelium minutum. I. Übersicht über die Aggregation und den Funktionswechsel der Zellen. Wilhelm Roux's Arch. Entwicklungs Mech. Org. 155: 342-357.

Gerisch, G., H. Fromm, A. Huesgen, and U. Wick. 1975. Control of cell-contact sites by cyclic AMP pulses in differentiating Dictyostelium cells. Nature 255: 547-549.

Harwood, A.J., N.A. Hopper, M.-N. Simon, S. Bouzid, M. Veron, and J.G. Williams. 1992a. Multiple roles for cAMP-dependent protein kinase during Dictyostelium development. Dev. Biol. 149: 90-99.

Harwood, A.J., N.A. Hopper, M.-N. Simon, D.M. Driscoll, M. Veron, and J.G. Williams. 1992b. Culmination in Dictyos. telium is regulated by the cAMP-dependent protein kinase Cell 69: 615-624.

Hopper, N.A., A.J. Harwood, S. Bouzid, M. Véron, and J.G. Williams. 1993. Activation of the prespore and spore cell pathway of Dictyostelium differentiation by cAMP dependent protein kinase and evidence for its upstream regulation by ammonia. $E M B O H$. (in press).

Klein, P.S., T.J. Sun, C.L. Saxe, A.R. Kimmel, R.L. Johnson, and P.N. Devreotes. 1988. A chemoattractant receptor controls development in Dictyostelium discoideum. Science 241: 1467-1472.

Mann, S.K.O. and R.A. Firtel. 1991. A developmentally regulated putative serine/threonine protein kinase is essential for development in Dictyostelium. Mech. Dev. 35: 89-101.

Mann, S.K.O., W.M. Yonemoto, S.S. Taylor, and R.A. Firtel. 1992. DdPK3, which plays essential roles during Dictyostelium development, encodes the catalytic subunit of cAMPdependent protein kinase. Proc. Natl. Acad. Sci. 89: 1070110705.

Mehdy, M.C., D. Ratner, and R.A. Firtel. 1983. Induction and modulation of cell type specific gene expression in Dictyos telium. Cell 32: 763-771.

Mutzel, R., M.L. Lacombe, M.-N. Simon, J. De Gunzburg, and M. Veron. 1987. Cloning and cDNA sequence of the regulatory subunit of cAMP-dependent protein kinase from Dictyostelium discoideum. Proc. Natl. Acad. Sci. 84: 6-10.

Nellen, W., S. Datta, C. Reymond, A. Sivertsen, S. Mann, T. Crowley, and R.A. Firtel. 1987. Molecular biology in Dictyostelium: Tools and applications. Methods Cell Biol. 28: 67100.

Pitt, G.S., N. Milona, J. Borleis, K.C. Lin, R.R. Reed, and P.N Devreotes. 1992. Structurally distinct and stage-specific adenylyl cyclase genes play different roles in Dictyostelium development. Cell 69: 305-315.

Raper, K.B. 1940. Pseudoplasmodium formation and organization in Dictyostelium discoideum. I. Elisha Mitchell Sci. Soc. 56: 241-282.

Roesler, W.J., G.R. Vandenbark, and R.W. Hanson. 1988. Cyclic AMP and the induction of eukaryotic gene transcription. /. Biol. Chem. 263: 9063-9066.

Salomon, Y. 1979. Adenylate cyclase assay. In Advances of cyclic nucleotide research (eds. G. Brooker, P. Greengard, and G.A. Robinson), Vol. 10, pp. 35-55. Raven Press, New York.

Saxe III, C.L., R.L. Johnson, P.N. Devreotes, and A.R. Kimmel. 1991. Multiple genes for cell surface cAMP receptors in Dictyostelium discoideum. Dev. Gen. 12: 6-13.

Schaap, P. and R. Van Driel. 1985. Induction of post-aggregative differentiation in Dictyostelium discoideum by cAMP. Evidence of involvement of the cell surface cAMP receptor. Exp. Cell. Res. 159: 388-398.

Schaap, P., T.M. Konijn, and P.J.M. Van Haastert. 1984. cAMP pulses coordinate morphogenetic movement during fruiting body formation of Dictyostelium minutum. Proc. Natl. Acad. Sci. 81: 2122-2126.

Schaap, P., M.M. Van Lookeren-Campagne, R. Van Driel, W. Spek, P.J.M. Van Haastert, and J. Pinas. 1986. Postaggregative differentiation induction by cyclic AMP in Dictyostelium: Intracellular transduction pathway and requirement for additional stimuli. Dev. Biol. 118: 52-63.

Schaap, P., M. Van Ments-Cohen, R.D.M. Soede, R. Brandt, R.A. Firtel, W. Dostman, H.-G. Genieser, B. Jastorff, and P.J.M. Van Haastert. 1993. Cell-permeable non-hydrolyzable cAMP derivatives as tools for analysis of signaling pathways controlling gene regulation in Dictyostelium. I. Biol. Chem. 268: 6323-6331.

Siegert, F. and C.J. Weijer. 1992. Three-dimensional scroll 
Pitt et al.

waves organize Dictyostelium slugs. Proc. Natl. Acad. Sci. 89: $6433-6437$.

Simon, M.-N., D. Driscoll, R. Mutzel, D. Part, J. Williams, and M. Véron. 1989. Overproduction of the regulatory subunit of the cAMP-dependent protein kinase blocks the differentiation of Dictyostelium discoideum. EMBO /. 8: 2039-2043.

Simon, M.-N., O. Pelegrini, M. Veron, and R.R. Kay. 1992. Mutation of protein kinase A causes heterochronic development of Dictyostelium. Nature 356: 171-172.

Tillinghast, H.S., Jr. and P.C. Newell. 1984. Retention of folate receptors on the cytoskeleton of Dictyostelium during development. FEBS Lett. 176: 325-330.

1987. Chemotaxis towards pteridines during development of Dictyostelium. I. Cell Sci. 87: 45-53.

Van Haastert, P.J.M. 1985. cAMP activates adenylate and guanylate cyclase of Dictyostelium discoideum cells by binding to different classes of cell surface receptors. A study with extracellular $\mathrm{Ca}^{2+}$. Biochim. Biophys. Acta 846: 324-333. 


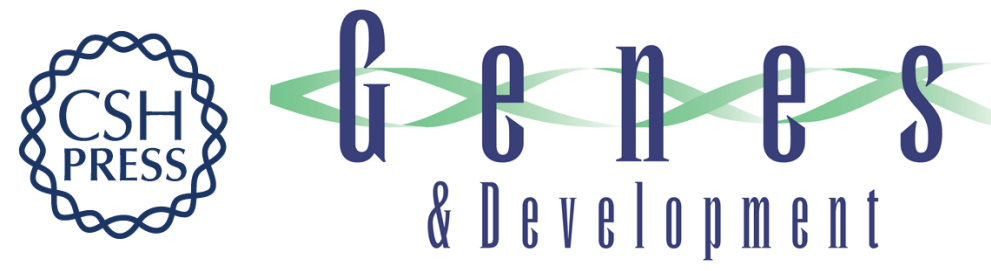

\section{Extracellular cAMP is sufficient to restore developmental gene expression and morphogenesis in Dictyostelium cells lacking the aggregation adenylyl cyclase (ACA).}

G S Pitt, R Brandt, K C Lin, et al.

Genes Dev. 1993, 7:

Access the most recent version at doi:10.1101/gad.7.11.2172

References This article cites 31 articles, 11 of which can be accessed free at:

http://genesdev.cshlp.org/content/7/11/2172.full.html\#ref-list-1

License

Email Alerting Service

Receive free email alerts when new articles cite this article - sign up in the box at the top right corner of the article or click here.

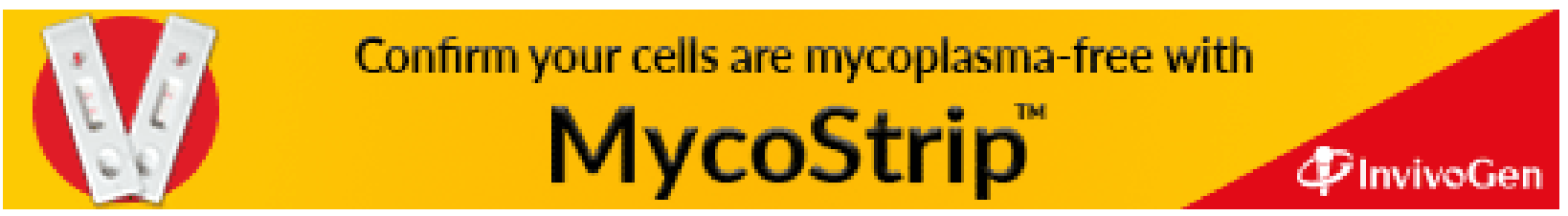

